\title{
Indice de la cubanidad programática siglo XIX
}

L A historia de Cuba en el siglo xix es una marcha lenta y penosa, pero siempre ascendente, hacia la independencia, por entre los breñales de la opresión española, el egoísmo de las potencias y la desesperación propia. En realidad los movimientos políticos carentes de sentido separatista no son más que étapas históricas de la peregrinación isleña hàcia esa meta; pero a cada período de ilusiones constitucionales corresponde un movimiento de tendencias liberales dentro de lo español. En pleno "colonialismo" lo advertimos ya en los planes de libertad mercantil y gobienno provincial de Francisco de Arango y Parreño y sus contemporáneos, 1 mientras que más tarde, avanzado el siglo XIX, se manifiesta bajo los nombres de "reformismo", primero, y "autonomismo", déspués. Por eso surgen como pilares indicadores de tales períodos los años de representación, o promesas, constitucionales. Por el contrario, a cada momento de engaño metropolitano y de ilusiones rotas, corresponde un recrudecimiento de las tendencias antiespañolas: si prevalece el sentimiento de la impotencia libertadora, o el interés plenamerite económico, se fortalece el anexionismo -orientado hacia México, Colombia o los Estados Unidos-; si predomina la fe en el esfuerzo propio se define la independencia. Pero a medida que el siglo avanza, la actitud de impotencia se marchita ante la resolución de minorías creadoras de un sentimiento nacional.

Desde los primeros años del siglo se acentúa la escisión entre criollos y españoles, escisión en la que "diferencias físicas y de carácter" tanto como "de intereses económicos" juegan un papel fundamental. Las luchas que siguen al intento de creación de una junta 
provincial en 1808 muestran la hondura de esas diferencias; pero, quizás, no tan cabalmente como las conspiraciones libertarias que comienzan casi inmediatamente. ${ }^{2}$

Es en esos años cuando empiezan a destacarse las figuras rectoras del pensamiento cubano no sólo de la época sino de todo el siglo. Además de nombres ya conocidos - por ejemplo, el del presbítero José Agustín Caballero--, hombres como Félix Varela, José de la Luz y Caballero, Gaspar Betancourt Cisneros, José Antonio Saco y otros, van a crear y a guiar la conciencia de varias generaciones con su enseñanza cívica y nacionalista. Dando normas de ejemplar democracia y ciudadanía escribía Varela en 1824:

Yo desearía que mis compatriotas (y doy este nombre no sólo a los naturales de mi país, sino a los que le han elegido por patria) tuviesen siempre por norma que en la Isla sólo deben distinguirse dos clases: los amigos de su prosperidad con preferencia a todos los países de la tierra, y los egoístas que sólo tratan de hacer su negocio aunque se arruine la Isla; en una palabra: patriotas y especuladores, y que el nacimiento no constituye a nadie ni en una ni en otra clase. ${ }^{3}$

Al año siguiente, como anticipando palabras de Saco, y dando ya expresión a las ideas de completa independencia política exclamaría :

... estoy contra la unión de la Isla a ningún gobierno, y desearía verla tan Isla en política como lo es en la naturaleza; ... todas las ventajas económicas y políticas están en favor de la revolución hecha exclusivamente por los de casa, y hacen que deba preferirse a la que pueda practicarse por el auxilio extranjero. 4

Con su independentismo franco de emigrado es obvio que Varela expresaba ideas imposibles de repetir públicamente por quienes vivían bajo la dominación española; pero el hecho significativo es que en tales palabras se evidenciaba el surgimiento definitivo de la conciencia de cubanidad.

En la década siguiente, en carta de 1833, Luz y Caballero subrayaba la necesidad de escribir textos escolares con "les couleurs du pays", 5 y en las mismas páginas, of reciendo lo que consideraba su divisa, y había de ser la de toda una centuria, exclamaba "Reunámonos, instruyámonos, mejorémonos; tengamos patria, tengamos patria." 6 
Es también entonces cuando la unidad de propósitos y el acercamiento de los hijos de la tierra van a salvar los límites de una clase social o una región, para abrazar a la isla entera. Refiriéndose a las rivalidades y celos naturales entre la capital y las provincias, decía a fines de 1938 Gaspar Betancourt Cisneros, una de las figuras próceres del siglo:

... todo debe sacrificarse a las simpatías cubanas: es preciso no of enderlos jamás [a los camagüeyanos] ni aún diciendo verdades útiles, porque nuestro gran propósito debe ser hermanar, estrechar lazos de amor y unión: un puebilo es todos los pueblos de la Isla. 7

En cuanto a la necesidad de una opinión nativa consciente y encauzada, se había expresado así tres meses antes:

... los del progreso no queremos precisamente que haya en Cuba populacho de ninguna clase; queremos un público, queremos un pueblo: público que dirija la opinión, pueblo que la entienda y obedezca. 8

Y sobre el término "cubano" diría más tarde cosas como éstas:

Ya sé que uno de ustedes es santiaguero (eso de cubano es una usurpación del título de los hijos de la Isla)...

... no podrá uno alborozarse como cubano y entristecerse como camagüeyano? Mi corazón me dice que sí..., hallo que es fortuna tener un corazón cubano para afectos y camagüeyano por suerte, sea cual fuere la ventura de cualquier rincón de. Cuba, yo me adjudico la partecita que me cabe, y me consuelo como si recayese directamente sobre el Camagüey... el todo no puede dejar de comprender a la parte, y yo estoy por el todo...9

A la prédica cívica y moral de esos grandes maestros de la época se unió, en los períodos de libertad, la enseñanza que desde las cátedras de política y constitución impartieron algunos como Varela; de modo que una gran actividad intelectual y política llena todo el siglo mostrando a una sociedad que se cohesionaba en unidad nacional. Por eso dice Medardo Vitier:

Los cubanos prominentes que a principios del siglo XIX proyectaban reformas políticas en la colonia, se fundaban para ello, en cierto grado de madurez que iba alcanzando la colectividad. El mero agregado humano cobraba fisonomía de nacionalidad, 
aunque incipiente todavía. Declarado o no por ellos, ese era el hecho sociológico...

Cuba, la mera colonia ultramarina, empezaba a percibir su propia entidad. Lo homogéneo y amorfo tornábase heterogéneo. 10

Lo que a través de los años hermana a todos esos hombres, sin distinción de credos políticos, es la voluntad de servir y el celo de conservar e incrementar — cuando no de crear- una actitud isleña. Un caso típico fué el de José A. Saco. En su maciza argumentación contra el régimen colonial y en particular contra la anexión, hay siempre en Saco una idea fundamental: Cuba; pero Cuba cubana. Y ello fué -además del símbolo de las clases rectoras de visión- un argumento terrible contra el anexionismo cuándo, para sobrevivir, la comunidad isleña cerraba sus filas, tratando de crearse un clima de sentido y emociones propios:

...debo decir francamente, que, a pesar de que reconozco las ventajas que Cuba alcanzaria, formando parte de aquellos Estados [Los Estados Unidos], me quedaría en el fondo del corazón un sentimiento secreto por la pérdida de la nacionalidad cubana. ... La anexión, en último resultado, no sería anexión, sino absorción de Cuba por los Estados Unidos. ... Yo quisiera que, si Cuba se separase, por cualquier evento, del tronco a que pertenece, siempre quedase para los cubanos y no para una raza extranjera. ... Yo desearía que Cuba no sólo fuese rica, ilustrada, moral y poderosa, sino que fuese Cuba cubana y no angloamericana. ${ }^{11}$

En otra parte de ese mismo trabajo contra la anexión, escrito en 1848, Saco, que había sido reformista, no separatista, con su aguda visión de los hechos exponía ạí la situación presente y futura de la isla:

Los pueblos, al paso que adelantan en civilización, van adquiriendo nuevas necesidades, y los que antes vivieran contentos con sólo los goces físicos, ya hoy tienen exigencias intelectuales, políticas y morales que satisfacer. La sabiduría de un buen gobierno consiste en observar atentamente estos progresos sociales, para poner en armonía con ellos las instituciones; pues resistir ciegamente, permaneciendo en la inmovilidad, es provocar una revolución. Cuba se va acercando ya al punto crítico, en que la cultura de sus moradores, y lo que es más alarmante todavía, la injusticia 
y los ultrajes que están sufriendo sus hijos, hacen imperiosa en ella una reforma política. ${ }^{12}$

La superación de tales necesidades físicas, y la intransigencia española ante la adquisición de otras nuevas de orden más elevado, no podían menos de llevar - como lo declaró Saco- a la revolución. Por eso el siglo xix cubano está plagado de conspiraciones: Es decir, que el cubano adquiere plena conciencia del acaecer histórico; y, -para usar una expresión de María Zambrano- ${ }^{13}$ no se deja atropellar por él sino que se le impone para crearlo y dirigirlo. Tal es el camino que lleva a la nación y al Estado a ese conglomerado social hasta entonces no unido en una visión y en un programa colectivos.

A semejante nacionalismo cívico y educacional no podía faltarle su correspondencia en las letras, como confirman las interesantes y poco estudiadas revistas de la época. ${ }^{14} \mathrm{En}$ su aspecto más moderado, tal actitud se expresó por la intención de hacer siempre las variaciones que indican nuestro carácter y nuestras costumbres, ${ }^{15}$ según el "Prospecto" de La Moda, mas cuando la intelectualidad criolla llega a coordinar sus aspiraciones en tendencias de temática insular el espiritu nacionalista adquiere mayor independencia y decisión.

Muy poco después del mencionado "Prospecto", en la Revista Bimestre Cubana, José Antonio Echeverria indicaba la necesidad de cubanizar la poesía. En comentario sobre un reciente poema descriptivo ${ }^{16}$ de Francisco Iturrondo decía Echeverría:

... concluiremos este artículo congratulándonos con que el "Can-
tor de la Alhambra" haya tenido la feliz idea de cubanizar, por
decirlo así, la poesía; aunque quisiéramos que su obrita hubiera
abrazado un campo más extenso, y la hubiese concebido bajo el
plan vastísimo de que es susceptible el pensamiento de describir
la naturaleza tropical de esta Isla; lo cual le habría dado ocasión
de entremezclar algunos episodios de costumbres, en que se viese
también al hombre de Cuba...17

La prueba de que la suya no era una opinión aislada la tenemos, por la misma época, en la "Exposición de las tareas de la Comisión Permanente de Literatura", a cargo de la revista. Porque en ella, entre otras noticias, se hace constar el hecho de que: 
Ha propendido por otra parte la Comisión a imprimir a su papel el carácter de cubano, cuyo epíteto le ha dado. ${ }^{18}$

El mismo espíritu animaba a La Cartera Cubana cuando, en limitación del material publicable, se declaraba el propósito de "tratar únicamente de La Habana, de la Isla, y de sus cosas, no acudiendo casi nunca a los extraños." 19 Y cuando al año siguiente se insistía

... en el empeño que tomamos a su publicación, de consagrarla exclusivamente al servicio de la. literatura del país. 20

Otro aspecto a primera vista más general -aunque no disidente del nacionalismo de época- fué la preocupación por el destino de la poesía y la misión social del poeta. En sus primeros tiempos, como ocurre en El Album, se considera al escritor "antes que poeta ... hombre", ${ }^{21}$ sin que se establezcan distinciones notables de tipo nacionalista, ${ }^{22}$ mientras que veinte y tres años más tarde, en Cuba Literaria, se acentúa el valor de "la historia de nuestra patria" así como la necesidad de que el poeta avive el amor a esa patria. ${ }^{23}$ A siete años de la Guerra Grande (1868-1878), y para el clima espiritual de la revista, bien se puede suponer cuál era el sentido de la palabra "patria", de manera que en las publicaciones más representativas posteriores a esa epopeya la cubanidad es ya un torrente avasallador. Si en el "Prospecto" de la Revista Cubana hay la aspiración cívica, de continuar en el espíritu de los que "nos han precedido y enseñado" conservando "siempre vivo el sentimiento cubano", ${ }^{24}$ en el número 45 , de diciembre de 1888, El Fígaro trae todo un programa literario, no ya cubano simplemente, sino patriótico, por el que la poesía y la cubanidad combatiente de la hora se confunden en un ideal de independencia:

Si la moderna poesía cubana - dice el anónimo articulista-, fiel a la tradición de sus más egregios cultivadores, aspira a ser el verbo de nuestro pueblo para perdurar en su corazón, no debe invocar a otra musa que a la religión del tiempo heroico: debe ser himno y elegía, hossanna de gloria y treno de apoteosis. El bardo de la nueva era debe completar el ciclo de poesía que se completa en la realidad de la historia. Heredia fué el heraldo precursor que señaló a su pueblo los horizontes de la tierra de promisión.' Luaces fué otro precursor, con sólo esta diferencia: que uno era 
cónđor libre y el otro águila prisionera, por lo que se limitó a presagiar el heró́smo cubano contando el heroísmo de griegos y polacos. - Ya el pueblo sabe ver en el cadalso un nuevo Tabor, sólo falta el poeta que consagre en el arte la epopeya grandiosa. 25

Con esa fusión encendida de ideal político y de poesía se está de lleno en el espíritu finisecular que ha de llevar a la independencia política. José Martí, símbolo luminoso de los tiempos en su acción y en su prédica, bosquejará, como Varela, la república "con todos y para el bien de todos", la patria "altar ... y no pedestal"; ${ }^{26}$ en tanto que su ideal literario, para América o para Cuba, será el de la más pura expresión propia:

... literatura no es otra cosa más que expresión y forma, y refleio en palabras de la Naturaleza que nutre y del espíritu que anima al pueblo que la crea.

O la literatura es cosa vacía de sentido, o es la expresión del pueblo que la crea.

La poesía vive de honra. ${ }^{27}$

La cubanidad como ideal es la consigna de los tiempos y el cauce subterráneo de que se nutren las formas varias de la actividad isleña. Por todo el siglo corre una urgencia tal de expresión propia, que la política igual que la poesía - "no art is more stubbornly national than poetry"- ${ }^{28}$ se quiebran en tendencias que no son sino sendas. E1 siglo xix isleño se explica, pues, en dos palabras: "cubano" y "hacer." Por eso resulta tan pletórico de valores, tan lleno de actividad intelectual y política, el siglo de oro de la nacionalidad aún no devenida estado. $Y$ por eso en su búsqueda la quinta esencia del pensamiento cubano acaba por identificarse con la independencia.

\section{Otto Olivera,} Tulane University, New Orleans.

\section{$\mathrm{N} O \mathrm{TAS}$}

1 Ramiro Guerra, Manual de historia de Cuba. La Habana. Cultural, 1938, I, 206.

2 Ibid., pp. 208-209, 219-222. 
3. Félix Varela, El habanero. La Habana. Universidad de La Habana, 1945 , p. 36

4 Ibid., pp. 103-105. I, 192.

5 De la vida intima. La Habana. Universidad de La Habana, 1945,

6 Ibid., p. 194. Como iluminadoras de la labor de Luz y Caballero son muy significativas las palabras de Julia Ward Howe, viajera estadounidense que visitó a don Pepe en La Habana: " $\mathrm{He}$ is a Liberal in politics and religion, a man of great reason and of great heart. In affairs of state, however, he meddles not, but contents himself with making statesmen. Like all wise Philanthropists, he sees the chief source of good to man in education, and devotes his life, and in a degree his fortune, to this object." $A$ Trip to Cuba. Boston. Ticknor and Fields, 1859, 128. El subrayado es nuestro.

7 Cartas del lugareño. La Habana. Dirección de Cultura, 1951, p. 42.

8 Ibid., p. 33.

9 Ibid., pp. 197, 236-237.

10 Las ideas en Cuba. La Habana. Editorial Trópico, 1938, I, 112.

11 Colección de papeles cientificos, históricos, políticos y de otros ramos sobre la isla de Cuba. París. Imprenta de D'Aubusson y Kugelmann, 18581859, III, 315-316.

12 Ibid., p. 329.

13 "La historia es un vehículo que no se detiene ni un instante. La cogemos en marcha si es que no nos atropella." "El nacimiento de la conciencia histórica." Cuadernos de la Universidad del Aire. La Habana. Editorial Lex, 1951, núm. 36, 44.

14 De ellas ha dicho Medardo Vitier: "Las Revistas constituyen un factor muy considerable en la formación intelectual cubana del siglo pasado... Las hay que son exponentes de la orientación de un momento o período histórico." Op. cit., I, 74 .

15 La Moda, I, (1829), 1.

16 "Rasgos descriptivos de la naturaleza cubana", (1831).

17 Vol. II, (1831), 130.

18 Ibid., p. 142.

19 "Plan de la obra", I, (1838), 7-8.

20 Ibid., II, (1839), 5. 
21 Vol. III, (1838), 18. Es un artículo de Domingo del Monte titulado: "Del destino de la poesía en el siglo xIx".

22 Se habla del "poeta castellano" en general. Ibid., p. 9.

23 Vol. x, (1861), 16.

24 Vol. I, (1885), 5. El autor es Enrique José Varona.

25 P. 8. Artículo anónimo titulado "Líneas".

26 Obras completas. La Habana. Editorial Lex, 1946, I, 697, 706.

27 Ibid., II, 342, 391; i, 823.

28 T. S. Eliot, "The Social Function of Poetry", Critiques and Essays in Criticism. New York. The Ronald Press Co., 1949, p. 112. 
